\title{
Association of impaired heart rate recovery with cardiopulmonary complications after lung cancer resection surgery
}

\author{
Duc Ha, MD, ${ }^{\mathrm{a}}$ Humberto Choi, MD, ${ }^{\mathrm{b}}$ Katrina Zell, MA, MS, ${ }^{\mathrm{c}}$ Daniel P. Raymond, MD, ${ }^{\mathrm{d}}$ \\ Kevin Stephans, MD, ${ }^{\mathrm{e}}$ Xiao-Feng Wang, $\mathrm{PhD},{ }^{\mathrm{c}}$ Gregory Videtic, MD, ${ }^{\mathrm{e}}$ Kevin McCarthy, R-CPT, \\ Omar A. Minai, MD, ${ }^{\mathrm{b}}$ and Peter J. Mazzone, MD, $\mathrm{MPH}^{\mathrm{b}}$
}

\begin{abstract}
Objectives: Patients who undergo lung resection surgery are at risk for postoperative morbidity and mortality. Appropriate selection of the surgical candidate is crucial in the treatment of lung cancer. Heart rate recovery is a measure of physical fitness. We aimed to investigate the association of impaired heart rate recovery with cardiopulmonary complications after lung resection surgery for treatment of lung cancer.
\end{abstract}

\begin{abstract}
Methods: Data from consecutive patients who, between 2009 and 2013, underwent heart rate recovery evaluation after 6-minute walk tests before lung resection surgery were retrospectively reviewed. Impaired heart rate recovery was defined as a 12-beat or less decrease in peak heart rate at 1 minute after the 6-minute walk test. Postoperative cardiopulmonary complications were as defined by the Society of Thoracic Surgeons General Thoracic Surgery Database. Logistic regression was performed, including previously known risk factors for postoperative complications after lung resection surgery.
\end{abstract}

Results: A total of 96 patients had heart rate recovery evaluated within 6 months of lung resection surgery for treatment of lung cancer. Thirty-one patients had impaired heart rate recovery, 17 of whom $(55 \%)$ had cardiopulmonary complications. A total of 65 patients had normal heart rate recovery, 17 of whom (26\%) had cardiopulmonary complications. In multivariable logistic regression analysis, impaired heart rate recovery was significantly associated with postoperative cardiopulmonary complications (odds ratio, 4.97; confidence interval, 1.79-13.8; $P=.002$ ). No patient died within 30 days after surgery.

Conclusions: Impaired heart rate recovery after the 6-minute walk test is associated with postoperative cardiopulmonary complications in patients who underwent lung resection surgery for treatment of lung cancer. (J Thorac Cardiovasc Surg 2015;149:1168-73)

See related commentary on page 1174 .
Surgery is the standard of care for managing patients with early-stage lung cancer. ${ }^{1}$ Unfortunately, only $20 \%$ to $25 \%$ of patients with lung cancer are able to undergo surgical resection, either because of the stage of the cancer at the time of diagnosis or because of comorbidities. ${ }^{1,2}$ The surgical mortality rate for patients undergoing lung

From the Medicine Institute, ${ }^{\mathrm{a}}$ Respiratory Institute, ${ }^{\mathrm{b}}$ Quantitative Health Sciences, Thoracic and Cardiovascular Surgery, ${ }^{\mathrm{d}}$ and Radiation Oncology, ${ }^{\mathrm{e}}$ Cleveland Clinic, Cleveland, Ohio.

Disclosures: Authors have nothing to disclose with regard to commercial support. Received for publication July 12, 2014; revisions received Oct 30, 2014; accepted for publication Nov 14, 2014; available ahead of print Jan 9, 2015.

Address for reprints: Duc Ha, MD, Cleveland Clinic, 9500 Euclid Ave NA10, Cleveland, OH 44195 (E-mail: ducha2011@gmail.com).

0022-5223/\$36.00

Copyright (c) 2015 by The American Association for Thoracic Surgery http://dx.doi.org/10.1016/j.jtcvs.2014.11.037 resection can be as high as $6.7 \%{ }^{3}$ Therefore, appropriate selection of surgical candidates for lung resection is crucial in the management of lung cancer to minimize postoperative morbidity and mortality while maximizing the number of patients who can undergo surgical resection.

Guideline-based preoperative assessment algorithms use pulmonary function testing and measures of cardiopulmonary fitness to risk stratify patients. ${ }^{1,2,4}$ Other predictors of mortality and major morbidity for lung cancer resection include body mass index (BMI), male gender, Zubrod performance status, renal dysfunction, induction chemotherapy, corticosteroid therapy, pneumonectomy, bilobectomy, and urgent procedures. ${ }^{5}$ Despite the numerous predictors of morbidity and mortality, controversy exists as to the optimal cutoff values for the variables tested and the identification of patients whose risk profile favors surgical versus nonsurgical management of early-stage lung cancer.

Heart rate recovery (HRR) is commonly used to evaluate autonomic activity and is thought to reflect one's physical fitness. It is typically evaluated after the 6-minute walk test (6MWT) and is measured as a reduction in heart rate in the first minute after cessation of exercise. An abnormal postexercise HRR is defined as a decline of 18 beats/min or less when exercise stops abruptly or 12 beats/min or 


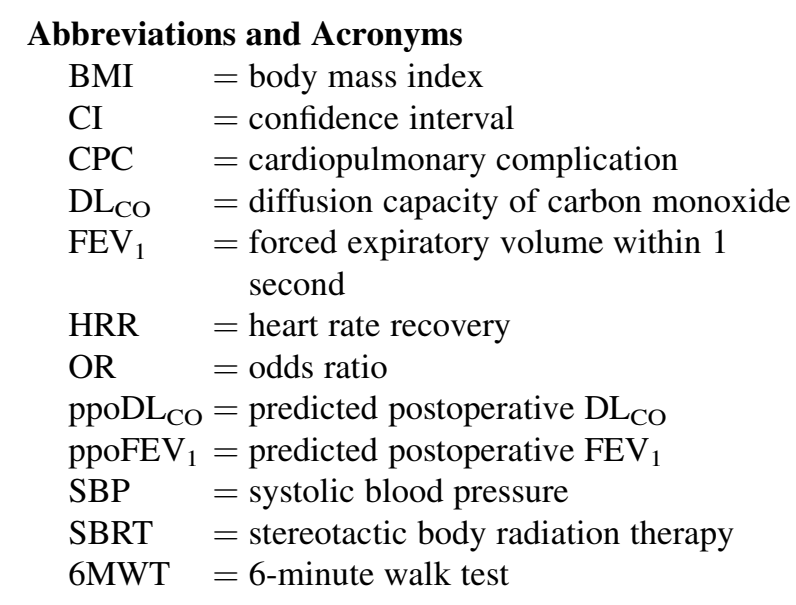

less when a cool-down period is used. ${ }^{6}$ In patients being considered for surgery, impaired HRR can suggest poor performance status/physical fitness and therefore increased surgical risk. We aim to investigate the association of impaired HRR with postoperative cardiopulmonary complications (CPCs) in patients who underwent lung resection for treatment of lung cancer. We hypothesize that impaired HRR is associated with an increased risk for postoperative CPCs.

\section{MATERIALS AND METHODS}

This study was approved by the Cleveland Clinic Institutional Review Board (Study \#13-317). We retrospectively reviewed consecutive patients who, between September 2009 and February 2013, underwent HRR evaluation after 6MWTs as part of their preoperative assessment for lung resection surgery at the Cleveland Clinic. 6MWTs and HRR evaluation were obtained at the discretion of the practicing pulmonologists. Data collected included age, gender, BMI, beta-blocker therapy, forced expiratory volume within 1 second $\left(\mathrm{FEV}_{1}\right) \%$ predicted, ${ }^{7}$ diffusion capacity of carbon monoxide ( $\left.\mathrm{DL}_{\mathrm{CO}}\right) \%$ predicted, ${ }^{8,9}$ type of surgery, predicted postoperative $\mathrm{FEV}_{1}\left(\mathrm{ppoFEV}_{1}\right)$, predicted postoperative $\mathrm{DL}_{\mathrm{CO}}$ $\left(\mathrm{ppoDL}_{\mathrm{CO}}\right)$, and predicted postoperative product. Postsurgical complications were recorded at our institution as part of the Society of Thoracic Surgeons General Thoracic Surgery Database (Appendix E1). Our primary end point was CPCs within 30 days after surgery; 30-day mortality was a secondary end point.

6MWTs were performed as suggested by the American Thoracic Society Pulmonary Function Standards Committee, ${ }^{10}$ modified to include HRR evaluation. Testing began after patients have been seated for 10 minutes. Pulse oximeters (Ohmeda Biox 3740 or Ohmeda 3900, Datex-Ohmeda Inc, Laurel, Md) with finger probes were used to obtain heart rates at different time intervals. HRR was defined as the difference in heart rate at the 6th minute of the 6MWT and 1 minute after completion of the test, with the patient in a seated position. Impaired HRR was defined as a 12-beat or less decrease in heart rate 1 minute into the cool-down period after the 6MWT, as suggested by previous literature. ${ }^{11}$ The segment method and quantitative lung perfusion scintigraphy (when available) were used to calculate $\mathrm{ppoFEV}_{1}$ and ppoDL $\mathrm{CO}^{12}$ Predicted postoperative product was calculated as the product of $\mathrm{ppoFEV}_{1}$ and $\mathrm{ppoDL}_{\mathrm{CO}} \cdot{ }^{13}$

Postoperative CPCs were as defined by the Society of Thoracic Surgeons General Thoracic Surgery Database, and included atelectasis, pleural effusion requiring drainage, acute respiratory distress syndrome, respiratory failure, mechanical ventilation at 48 hours postoperatively, deep vein thrombosis/pulmonary embolism, pneumothorax, pneumonia, empyema, atrial or ventricular arrhythmias, and myocardial infarction.

To assess the generalizability of this predictor, we analyzed the HRR of patients who underwent stereotactic body radiation therapy (SBRT) for treatment of lung cancer. Patients were selected for SBRT after it was determined that they had too high a risk for surgical resection based on traditional measures of cardiopulmonary fitness and discussion at our institutional tumor board.

\section{Statistical Analysis}

Descriptive statistics were summarized as means and standard deviations for all continuous variables and as counts and percentages for all categoric variables. The Student $t$ test and Pearson's chi-square tests were used to compare baseline characteristics of our patient cohort with other patients with lung cancer who underwent surgical resection in the same time period. Univariable logistic regression analyses were performed on all independent variables that could contribute to the composite outcome of interest (CPCs). Multivariable logistic regression analyses, using a stepwise approach, were performed on independent variables whose $P$ values were less than .1 in univariable logistic regression analyses. A maximum number of 3 covariates were used in each multivariable logistic regression analysis, keeping with an approximately 11:1 patient-to-event ratio. Independent variables were retained in the models if they were statistically significant and nonlinear to other covariables, with the exception of beta-blocker therapy, which was included in the model regardless of statistical significance due to possible interaction with HRR. Odds ratios (ORs) and $95 \%$ confidence intervals (CIs) were used whenever appropriate. All analyses were 2-tailed. Statistical significance in the multivariable models was defined as the difference in Akaike information criterion having a $P<.05$. Receiver operating characteristic curves were generated to assess the HRR's ability to predict postoperative CPCs. Because the optimal cutoff for impaired HRR in the patient population with lung cancer is unknown, the Youden method was used to confirm the optimal cutoff for HRR in predicting CPCs. ${ }^{14}$ SAS 9.3 and JMP Pro software (SAS Institute Inc, Cary, NC) were used for all analyses.

\section{RESULTS}

A total of 571 patients underwent surgical resection for lung cancer during the study period, $96(16.5 \%)$ of whom had HRR data available. Compared with other patients who underwent lung resection within the same time period, patients who had HRR evaluation after 6MWTs did not have statistically significant differences in age, gender, BMI, corticosteroid therapy, preoperative chemotherapy, history of cardiothoracic surgery, creatinine and hemoglobin levels, $\mathrm{FEV}_{1}, \mathrm{DL}_{\mathrm{CO}}$, performance status, and clinical stage (Table E1).

Of those who had HRR evaluation, 34 (35\%) had a total of 42 postoperative CPCs (Table E2). There were no significant differences in patient characteristics and standard pulmonary function measures between those with and without CPCs, including $\mathrm{FEV}_{1} \%$ predicted, $\mathrm{DL}_{\mathrm{CO}} \%$ predicted, ppoFEV ${ }_{1}, \mathrm{ppoDL}_{\mathrm{CO}}$, and predicted postoperative product. The majority $(86 \%)$ of patients had clinical stage I or II lung cancer. A higher number of patients in the CPC group had clinical stage III disease (7 vs 2). One patient had oliogometastatic disease. There was no difference in tumor location or type of surgery 
TABLE 1. Baseline characteristics

\begin{tabular}{|c|c|c|c|c|}
\hline Patient characteristics & Total $(n=96)$ & No CPC $(n=62)$ & $\mathrm{CPC}(\mathrm{n}=34)$ & $P$ value \\
\hline Age, y & $65.5 \pm 9.6$ & $64.8 \pm 9.2$ & $66.7 \pm 10.4$ & .30 \\
\hline Gender, n (\%) & & & & .33 \\
\hline Female & $46(47.9)$ & $32(51.6)$ & $14(41.2)$ & \\
\hline Race, n (\%) & & & & .51 \\
\hline African American & $9(9.4)$ & $7(11.3)$ & $2(5.9)$ & \\
\hline Caucasian & $86(89.6)$ & $54(87.1)$ & $32(94.1)$ & \\
\hline BMI, $\mathrm{kg} / \mathrm{m}^{2}$ & $27.8 \pm 5.2$ & $27.8 \pm 5.3$ & $27.9 \pm 4.9$ & .85 \\
\hline Smoking history, $\mathrm{n}(\%)$ & & & & .76 \\
\hline Current & $24(25.0)$ & $17(27.4)$ & $7(20.6)$ & \\
\hline Former & $67(69.8)$ & $42(67.7)$ & $25(73.5)$ & \\
\hline Pack-y & $43.3 \pm 27.5$ & $412 \pm 25.8$ & $47.2 \pm 30.5$ & .46 \\
\hline \multicolumn{5}{|l|}{ Medical history, n (\%) } \\
\hline COPD & $41(42.7)$ & $23(37.1)$ & $18(52.9)$ & .13 \\
\hline CKD & $4(4.2)$ & $2(3.2)$ & $2(5.9)$ & .53 \\
\hline Atrial arrhythmia & $6(6.3)$ & $4(6.5)$ & $2(5.9)$ & .91 \\
\hline Prior CT surgery & $16(16.7)$ & $10(16.1)$ & $6(17.6)$ & .85 \\
\hline \multicolumn{5}{|l|}{ Medications, n (\%) } \\
\hline Beta-blockers & $24(25.3)$ & $18(29.0)$ & $6(18.2)$ & .25 \\
\hline Corticosteroid & $10(10.4)$ & $3(4.8)$ & $7(20.6)$ & .016 \\
\hline \multicolumn{5}{|l|}{ Zubrod PS, n (\%) } \\
\hline 0 & $20(20.8)$ & $11(17.7)$ & $9(26.5)$ & .47 \\
\hline 1 & $75(78.1)$ & $50(80.6)$ & $25(73.5)$ & \\
\hline 2 & $1(1.0)$ & $1(1.6)$ & $0(0)$ & \\
\hline \multicolumn{5}{|l|}{ Laboratory values } \\
\hline Creatinine, mg/dL & $0.9 \pm 0.3$ & $0.8 \pm 0.2$ & $1.0 \pm 0.4$ & .19 \\
\hline Hemoglobin, g/dL & $13.3 \pm 1.4$ & $13.2 \pm 1.5$ & $13.3 \pm 1.3$ & .86 \\
\hline \multicolumn{5}{|l|}{ PFTs } \\
\hline FVC, \% predicted & $92.6 \pm 15.0$ & $92.5 \pm 14.7$ & $92.7 \pm 15.9$ & .81 \\
\hline $\mathrm{FEV}_{1}, \%$ predicted & $81.5 \pm 20.1$ & $82.7 \pm 20.2$ & $79.2 \pm 20.0$ & .51 \\
\hline $\mathrm{DL}_{\mathrm{CO}}, \%$ predicted & $71.0 \pm 16.9$ & $70.5 \pm 15.6$ & $71.9 \pm 19.4$ & .82 \\
\hline \multicolumn{5}{|l|}{ PPO lung function } \\
\hline \multicolumn{5}{|l|}{ By segments $(\mathrm{n}=96)$} \\
\hline ppoFEV $_{1}, \%$ predicted & $62.3 \pm 22.1$ & $62.7 \pm 23.1$ & $61.5 \pm 20.5$ & .89 \\
\hline ppoDL $_{\mathrm{CO}}, \%$ predicted & $55.1 \pm 16.9$ & $55.8 \pm 15.8$ & $53.8 \pm 18.9$ & .33 \\
\hline PPP & $3662.4 \pm 2059.0$ & $3685.4 \pm 2013.5$ & $3621.4 \pm 2169.9$ & .73 \\
\hline \multicolumn{5}{|l|}{ By perfusion $(\mathrm{n}=46)$} \\
\hline ppoFEV $_{1}, \%$ predicted & $58.7 \pm 19.1$ & $62.2 \pm 20.2$ & $51.4 \pm 14.7$ & .19 \\
\hline $\operatorname{ppoDL}_{\mathrm{CO}}, \%$ predicted & $52.0 \pm 14.4$ & $54.0 \pm 15.0$ & $48.1 \pm 13.0$ & .19 \\
\hline PPP & $3201.2 \pm 1805.4$ & $3536.9 \pm 2024.5$ & $2530.0 \pm 1019.8$ & .19 \\
\hline Clinical stage, $\mathrm{n}(\%)$ & & & & .017 \\
\hline Ia & $41(43.2)$ & $30(49.2)$ & $11(32.4)$ & \\
\hline $\mathrm{Ib}$ & $20(21.1)$ & $14(23.0)$ & 7 (20.6) & \\
\hline IIa & $15(15.8)$ & $9(14.8)$ & $6(17.6)$ & \\
\hline $\mathrm{IIb}$ & $7(7.4)$ & $6(9.7)$ & $2(5.9)$ & \\
\hline IIIa & $8(8.3)$ & $2(3.2)$ & $6(17.6)$ & \\
\hline $\mathrm{IIIb}$ & $1(1.1)$ & $0(0.0)$ & $1(2.9)$ & \\
\hline IV & $1(1.1)$ & $0(0.0)$ & $1(2.9)$ & \\
\hline Nodal stage, n (\%) & & & & .07 \\
\hline N0 & $77(80.2)$ & $54(87.1)$ & $23(67.6)$ & \\
\hline N1 & $14(14.6)$ & $6(9.7)$ & $8(23.5)$ & \\
\hline $\mathrm{N} 2$ & $5(5.2)$ & $2(3.2)$ & $3(8.8)$ & \\
\hline Type of surgery, $n(\%)$ & & & & .86 \\
\hline Segmentectomy & $13(13.5)$ & $9(14.5)$ & $4(11.8)$ & \\
\hline Lobectomy & $64(66.7)$ & $40(64.5)$ & $24(70.6)$ & \\
\hline Bilobectomy & $5(5.2)$ & $4(6.5)$ & $1(2.9)$ & \\
\hline Pneumonectomy & $14(14.6)$ & $9(14.5)$ & $5(14.7)$ & \\
\hline
\end{tabular}


TABLE 1. Continued

\begin{tabular}{|c|c|c|c|c|}
\hline Patient characteristics & Total $(n=96)$ & No CPC $(n=62)$ & CPC $(n=34)$ & $P$ value \\
\hline Laterality, n (\%) & & & & .48 \\
\hline Left & $38(40.0)$ & $26(42.6)$ & $12(35.3)$ & \\
\hline Location, n (\%) & & & & .63 \\
\hline Upper & $56(58.3)$ & $34(54.8)$ & $22(64.7)$ & \\
\hline Middle & $7(7.3)$ & $5(8.1)$ & $2(5.9)$ & \\
\hline Lower & $31(32.3)$ & $21(33.9)$ & $10(29.4)$ & \\
\hline
\end{tabular}

Values are expressed as means and standard deviation or as specified. BMI, Body mass index; $C K D$, chronic kidney disease; $C O P D$, chronic obstructive pulmonary disease; $C P C$, cardiopulmonary complication; $C T$, cardiothoracic; $D L_{C O}$, diffusion capacity of carbon monoxide; $F E V_{l}$, forced expiratory volume within 1 second; $F V C$, forced vital capacity; $P F T$, pulmonary function test; $P P O$, predicted postoperative; $P P P$, predicted postoperative product; $P S$, performance status.

(Table 1). Patients with and without CPCs also had similar 6-minute walk distance, Borg dyspnea scores, and changes in oxygen saturation during the 6MWT (Table 2).

Sixty-five patients $(68 \%)$ had normal HRR, and 31 patients $(32 \%)$ had impaired HRR. Of those with impaired HRR, $17(55 \%)$ had postoperative CPCs. The calculated univariate OR for impaired HRR with CPCs was 3.43 $(P=.007)$. Oral corticosteroid therapy and preoperative creatinine levels were also significantly associated with CPCs (Table 3). Variables that had $P$ values less than .1 and were therefore also considered for multivariable logistic regression analysis included nodal stage, ppoFEV $_{1}$, pre-6MWT diastolic blood pressure, and change in systolic blood pressure (SBP). In multivariable logistic regression analysis, impaired HRR was significantly associated with postoperative CPCs (OR, 4.97; CI, 1.79-13.8; $P=.002$ ) (Table 3). Those with CPCs also had larger changes in
SBP during the 6MWT compared with those without CPCs (OR, 1.03; CI, 1.00-1.07; $P=.03$ ); no other variables were significantly associated with CPCs in multivariable logistic regression analysis. The model, which included beta-blocker therapy, change in SBP, and impaired HRR, had an area under the receiver operating characteristic curve of 0.73 for predicting postoperative CPCs. On the basis of our data (Figure E1), the optimal cutoff for HRR in predicting CPCs in patients with lung cancer was -13 (sensitivity 0.56 and specificity 0.73 ), similar to previous cutoffs in other patient populations.

Nine patients had postoperative atrial arrhythmias. When patients with a history of atrial fibrillation or atrial flutter identified before surgery were excluded, impaired HRR was still significantly associated with postoperative CPCs (OR, 3.58; CI, 1.33-9.63; $P=.012$ ). No patient died within 30 days after lung resection surgery.

TABLE 2. Six-minute walk test measurements

\begin{tabular}{|c|c|c|c|c|}
\hline 6MWT measurements & Total $(n=96)$ & No CPC $(n=62)$ & $\mathrm{CPC}(\mathrm{n}=34)$ & $P$ value \\
\hline \multicolumn{5}{|l|}{ Blood pressure, $\mathrm{mm} \mathrm{Hg}$} \\
\hline Pre-6MWT SBP & $133.1 \pm 25.8$ & $135.3 \pm 18.3$ & $129.2 \pm 35.7$ & .88 \\
\hline Pre-6MWT DBP & $74.7 \pm 14.8$ & $76.7 \pm 9.8$ & $71.0 \pm 20.7$ & .26 \\
\hline Post-6MWT SBP & $148.9 \pm 24.3$ & $148.5 \pm 19.7$ & $149.8 \pm 31.3$ & .34 \\
\hline Post-6MWT DBP & $78.6 \pm 14.1$ & $80.3 \pm 11.9$ & $75.3 \pm 17.0$ & .22 \\
\hline Change in SBP & $+15.8 \pm 18.6$ & $+13.2 \pm 15.1$ & $+20.6 \pm 23.3$ & .13 \\
\hline Change in DBP & $+3.8 \pm 10.7$ & $+3.6 \pm 7.8$ & $+4.3 \pm 14.7$ & .83 \\
\hline \multicolumn{5}{|l|}{ Oxygen saturation, $\%$} \\
\hline Pre-6MWT & $96.3 \pm 2.4$ & $96.1 \pm 2.7$ & $96.5 \pm 1.7$ & .58 \\
\hline During 6MWT & $94.5 \pm 2.7$ & $94.6 \pm 2.9$ & $94.3 \pm 2.3$ & .37 \\
\hline Change & $-1.8 \pm 2.4$ & $-1.5 \pm 2.3$ & $-2.2 \pm 2.5$ & .16 \\
\hline \multicolumn{5}{|l|}{ Distance } \\
\hline $6 \mathrm{MWD}, \mathrm{ft}$ & $1295.2 \pm 290.4$ & $1318.5 \pm 296.5$ & $1253.5 \pm 278.6$ & .32 \\
\hline$\%$ predicted & $79.9 \pm 16.2$ & $81.9 \pm 15.8$ & $76.4 \pm 16.6$ & .045 \\
\hline Borg dyspnea score & $1.5 \pm 1.5$ & $1.4 \pm 1.2$ & $1.8 \pm 1.9$ & .51 \\
\hline \multicolumn{5}{|l|}{ Heart rate, beats/min } \\
\hline Resting & $84.8 \pm 16.1$ & $85.0 \pm 15.3$ & $84.5 \pm 17.7$ & .57 \\
\hline During 6MWT & $107.4 \pm 13.9$ & $107.5 \pm 12.6$ & $107.1 \pm 16.2$ & .75 \\
\hline Change & $+22.6 \pm 13.1$ & $+22.6 \pm 13.1$ & $+22.6 \pm 13.3$ & .96 \\
\hline HRR-1 min & $-16.0 \pm 9.7$ & $-17.0 \pm 9.8$ & $-14.2 \pm 9.3$ & .077 \\
\hline Impaired HRR, n (\%) & $31(32.3)$ & $14(22.6)$ & $17(50.0)$ & .006 \\
\hline
\end{tabular}

Values are expressed as means and standards of deviation unless specified. $C P C$, Cardiopulmonary complication; $D B P$, diastolic blood pressure; $H R R$, heart rate recovery; $H R R-1 \mathrm{~min}$, HRR at 1 minute post-6MWT; $S B P$, systolic blood pressure; $6 M W D$, 6-minute walk distance; $6 M W T$, 6-minute walk test. 
TABLE 3. Analyses of association with cardiopulmonary complications

\begin{tabular}{|c|c|c|}
\hline \multirow[b]{2}{*}{ Variables } & \multicolumn{2}{|c|}{ Results } \\
\hline & OR $(95 \%$ CI $)$ & $P$ value \\
\hline \multicolumn{3}{|l|}{ Univariable analysis } \\
\hline Beta-blocker therapy & $0.54(0.19-1.54)$ & .25 \\
\hline Corticosteroid therapy & $5.10(1.23-21.2)$ & .025 \\
\hline Creatinine & $5.06(1.06-24.0)$ & .041 \\
\hline Nodal clinical stage & & .084 \\
\hline N1 vs N0 & $3.13(0.98-10.0)$ & \\
\hline $\mathrm{N} 2$ vs N0 & $3.52(0.55-22.5)$ & \\
\hline ppoFEV $_{1}$ (perfusion) & $0.96(0.92-1.01)$ & .083 \\
\hline Pre-6MWT DBP & $0.97(0.94-1.01)$ & .096 \\
\hline Change in SBP & $5.10(1.23-21.2)$ & .085 \\
\hline Impaired HRR & $3.43(1.40-8.42)$ & .007 \\
\hline \multicolumn{3}{|l|}{ Multivariable analysis } \\
\hline Beta-blocker therapy & $0.35(0.11-1.15)$ & .08 \\
\hline Change in SBP & $1.03(1.00-1.07)$ & .03 \\
\hline Impaired HRR & $4.97(1.79-13.8)$ & .002 \\
\hline
\end{tabular}

Forty-nine patients who were considered high risk for surgery and therefore received SBRT for treatment of early-stage lung cancer between 2009 and 2012 had HRR data available. Compared with patients who underwent surgical resection, those who received SBRT were older and had lower $\mathrm{FEV}_{1}, \mathrm{DL}_{\mathrm{CO}}$, and predicted postoperative product. Thirty-two $(65 \%)$ of the patients who were selected for SBRT had impaired HRR (Table E3).

\section{DISCUSSION}

Our study aimed to investigate the association of HRR after the 6MWT with postoperative CPCs in patients who underwent lung resection surgery for treatment of lung cancer. In multivariable logistic regression analyses that included many of the variables previously shown to be associated with postoperative complications for patients undergoing major thoracic surgery, impaired HRR was associated with a 4.97 -fold increase in the odds of having postoperative CPCs. This result is particularly notable because the surgical group was already highly selected on the basis of traditional measures of cardiopulmonary fitness.

Impaired HRR has been shown to predict mortality independently of coronary artery disease, ${ }^{15}$ mortality in patients with congestive heart failure, ${ }^{16}$ and severity of coronary artery disease. ${ }^{17}$ In addition, it has been shown to be predictive of clinical worsening in patients with pulmonary arterial hypertension, ${ }^{18}$ as well as the development of pulmonary hypertension and mortality in patients with idiopathic pulmonary fibrosis. ${ }^{19,20}$ To the best of our knowledge, no previous study has investigated the association of HRR with postoperative CPCs in patients undergoing lung resection surgery for treatment of lung cancer.

HRR is traditionally thought to reflect an individual's overall physical fitness. In the postoperative setting, CPCs can develop in patients with impaired HRR if they are unable to participate in physical therapy or ambulate because of poor fitness. Inactivity could lead to a higher risk of developing some of the CPCs that may not seem to have a direct link to this measure (eg, atelectasis, respiratory failure, deep vein thrombosis/pulmonary embolism).

The balance in the increase and normalization of heart rate in exercising individuals is thought to be mediated by the sympathetic and parasympathetic autonomic systems. HRR is thought to be mediated by reactivation of the parasympathetic autonomic system after exercise, with a poor HRR implying an excess of sympathetic activation and a lack of parasympathetic reactivation. Therefore, the use of beta-adrenergic blockers theoretically would not affect HRR. This theory is supported by previous data that showed the use of beta-blockers has no impact on the prognostic value of HRR. ${ }^{11,18,20,21}$ It is affirming that even in a multivariable model that included beta-blocker therapy as a covariate, impaired HRR was still associated with postoperative CPCs. Although potentially influenced by atrial arrhythmias, our analysis did not confirm this concern. The relationship of impaired HRR and postoperative CPCs existed even with exclusion of patients who had atrial fibrillation or atrial flutter.

HRR is not routinely evaluated in all pulmonary function laboratories, limiting our ability to validate our findings. We chose to assess the generalizability of impaired HRR and CPCs by separately identifying patients deemed to have too high a risk for resection on the basis of conventional measures, who were recommended to undergo SBRT instead of surgery. We found that those with medically inoperable early-stage lung cancer were more likely to have impaired HRR than those who underwent surgical resection $(65 \%$ vs $32 \%)$, suggesting that impaired HRR could be used as a marker of poor surgical fitness.

In addition to HRR, a larger increase in SBP during the 6MWT seems to be associated with postoperative CPCs. During exercise, parasympathetic activity allows for autoregulation of blood pressure. Therefore, it is not surprising that if there is autonomic dysfunction (as in the case of patients with impaired HRR), there is also impaired blood pressure control during exercise. High SBP during exercise and impaired HRR could be the by-product of the same impaired physiology in an individual at risk for postoperative complications. To the best of our knowledge, no previous studies have assessed changes in blood pressure during the 6MWT for predicting postsurgical complications. The OR (1.03) suggests an approximately $3 \%$ increased odds of having CPCs for every $1 \mathrm{~mm} \mathrm{Hg}$ 
increase in SBP above the average response in patients without CPCs. In our study, patients with CPCs had an increase in SBP approximately $7 \mathrm{~mm} \mathrm{Hg}$ higher than those without CPCs. Our data suggest that in patients who undergo lung resection surgery, oral corticosteroid therapy and creatinine levels are also associated with postoperative complications, consistent with the previous literature. ${ }^{5}$ In multivariable logistic regression analyses, these variables no longer appear to be associated with postoperative complications.

The American College of Chest Physicians recommends that in patients with ppoFEV ${ }_{1}$ or ppoDL $\mathrm{CO}_{\mathrm{CO}}$ between $30 \%$ and $60 \%$ predicted, a low technology exercise test with stair climbing or shuttle walk test is recommended; cardiopulmonary exercise testing is recommended in those with ppoFEV $_{1}$ or ppoDL $\mathrm{CO}_{\mathrm{CO}}$ or both less than $30 \%$. $^{3}$ The 6MWT is a simple and relatively low-cost test in which HRR can be readily measured. Performance of a 6MWT is more common in many pulmonary function laboratories than the shuttle walk test or formalized stair climbing test.

\section{Study Limitations}

Our study is limited by its retrospective nature. We describe an association between impaired HRR and the risk of CPCs that could be useful in preoperative risk assessment. Although we included many of the variables previously shown to be associated with postoperative morbidity and mortality, we were limited by the number of available patients and events, and therefore, the number of variables to be included in our logistic regression analysis. The decision to perform 6MWTs and HRR evaluation was made by the practicing pulmonologist; therefore, our study sample is subject to selection bias. It would be useful to validate our findings in a prospective cohort study. In addition, it is difficult to directly connect impaired HRR to some of the CPCs included in our study. Last, although HRR is useful for predicting postoperative complications, it is unclear whether it would predict postoperative mortality or quality of life, the most important end points in the preoperative assessment.

Our study has several strengths. First, we predefined our outcome of interest using a standard definition of CPCs. Second, we included many of the important predictors of postoperative morbidity and mortality in thoracic surgery in our dataset. Third, we tested for potential differences in predictors of complications between our study cohort and other patients with lung cancer who received surgical resection within the same time period, allowing for generalizability of our findings to other surgical patients. The next step in validating this marker of risk would be to include HRR in an algorithm for the physiologic evaluation of patients with lung cancer being considered for resection surgery and determine its impact on decision-making and outcomes.

\section{CONCLUSIONS}

Impaired HRR after the 6MWT is associated with postoperative CPCs in patients with lung cancer undergoing lung resection surgery. HRR could be included in the assessment of operative risk in this group of patients.

\section{References}

1. Howington JA, Blum MG, Chang AC, Balekian AA, Murthy SC. Treatment of stage I and II non-small cell lung cancer: diagnosis and management of lung cancer, 3rd ed: American college of chest physicians evidence-based clinical practice guidelines. Chest. 2013;143(5 suppl):e278S-313S.

2. Brunelli A, Charloux A, Bolliger CT, Rocco G, Sculier JP, Varela G, et al. ERS/ ESTS clinical guidelines on fitness for radical therapy in lung cancer patients (surgery and chemo-radiotherapy). Eur Respir J. 2009;34:17-41.

3. Brunelli A, Kim AW, Berger KI, Addrizzo-Harris DJ. Physiologic evaluation of the patient with lung cancer being considered for resectional surgery: diagnosis and management of lung cancer, 3rd ed: American college of chest physicians evidence-based clinical practice guidelines. Chest. 2013;143(5 suppl): e166S-90S.

4. Lim E, Baldwin D, Beckles M, Duffy J, Entwisle J, Faivre-Finn C, et al Guidelines on the radical management of patients with lung cancer. Thorax 2010;65(Suppl 3):iii1-27.

5. Kozower BD, Sheng S, O’Brien SM, Liptay MJ, Lau CL, Jones DR, et al. STS database risk models: Predictors of mortality and major morbidity for lung cancer resection. Ann Thorac Surg. 2010;90:875-83.

6. Pichurko BM. Exercising your patient: which test(s) and when? Respir Care. 2012;57:100-13

7. Hankinson JL, Odencrantz JR, Fedan KB. Spirometric reference values from a sample of the general U.S. population. Am J Respir Crit Care Med. 1999;159: 179-87.

8. Miller A, Thornton JC, Warshaw R, Anderson H, Teirstein AS, Selikoff IJ. Single breath diffusing capacity in a representative sample of the population of Michigan, a large industrial state. predicted values, lower limits of normal, and frequencies of abnormality by smoking history. Am Rev Respir Dis. 1983;127:270-7.

9. Miller MR, Hankinson J, Brusasco V, Burgos F, Casaburi R, Coates A, et al. Standardisation of spirometry. Eur Respir J. 2005;26:319-38.

10. ATS Committee on Proficiency Standards for Clinical Pulmonary Function Laboratories. ATS statement: Guidelines for the six-minute walk test. Am J Respir Crit Care Med. 2002;166:111-7.

11. Cole CR, Blackstone EH, Pashkow FJ, Snader CE, Lauer MS. Heart-rate recovery immediately after exercise as a predictor of mortality. $N$ Engl J Med. 1999;341:1351-7.

12. Markos J, Mullan BP, Hillman DR, Musk AW, Antico VF, Lovegrove FT, et al Preoperative assessment as a predictor of mortality and morbidity after lung resection. Am Rev Respir Dis. 1989;139:902-10.

13. Pierce RJ, Copland JM, Sharpe K, Barter CE. Preoperative risk evaluation for lung cancer resection: predicted postoperative product as a predictor of surgical mortality. Am J Respir Crit Care Med. 1994;150:947-55.

14. Perkins NJ, Schisterman EF. The Youden index and the optimal cut-poin corrected for measurement error. Biom J. 2005;47:428-41.

15. Vivekananthan DP, Blackstone EH, Pothier CE, Lauer MS. Heart rate recovery after exercise is a predictor of mortality, independent of the angiographic severity of coronary disease. J Am Coll Cardiol. 2003;42:831-8.

16. Tang YD, Dewland TA, Wencker D, Katz SD. Post-exercise heart rate recovery independently predicts mortality risk in patients with chronic heart failure. J Card Fail. 2009;15:850-5.

17. Ghaffari S, Kazemi B, Aliakbarzadeh P. Abnormal heart rate recovery after exercise predicts coronary artery disease severity. Cardiol J. 2011;18:47-54.

18. Minai OA, Gudavalli R, Mummadi S, Liu X, McCarthy K, Dweik RA. Heart rate recovery predicts clinical worsening in patients with pulmonary arterial hypertension. Am J Respir Crit Care Med. 2012;185:400-8.

19. Swigris JJ, Olson AL, Shlobin OA, Ahmad S, Brown KK, Nathan SD. Heart rate recovery after six-minute walk test predicts pulmonary hypertension in patients with idiopathic pulmonary fibrosis. Respirology. 2011;16:439-45.

20. Swigris JJ, Swick J, Wamboldt FS, Sprunger D, du Bois R, Fischer A, et al. Hear rate recovery after 6-min walk test predicts survival in patients with idiopathic pulmonary fibrosis. Chest. 2009;136:841-8.

21. Shetler K, Marcus R, Froelicher VF, Vora S, Kalisetti D, Prakash M, et al. Heart rate recovery: validation and methodologic issues. J Am Coll Cardiol. 2001;38: 1980-7. 


\section{APPENDIX E1. DEFINITIONS OF POSTOPERATIVE COMPLICATIONS ACCORDING TO THE SOCIETY OF THORACIC SURGEONS GENERAL THORACIC SURGERY DATABASE}

Unexpected return to operating room, chest tube air leak, atelectasis, pleural effusion, pneumonia, acute respiratory distress syndrome, respiratory failure, bronchopleural fistula, pulmonary embolus, pneumothorax, prolonged mechanical ventilation ( $>48$ hours), reintubation, tracheostomy, atrial arrhythmia, ventricular arrhythmia, myocardial infarction, deep vein thrombosis, gastric outlet obstruction, ileus, anastomotic leak, esophageal dilation, urinary tract infection, discharged with urinary catheter, empyema, infected surgical site, wound infection, sepsis, paralysis, delirium tremens, renal failure, chylothorax, requiring blood transfusion, and units of packed blood cells transfused. 


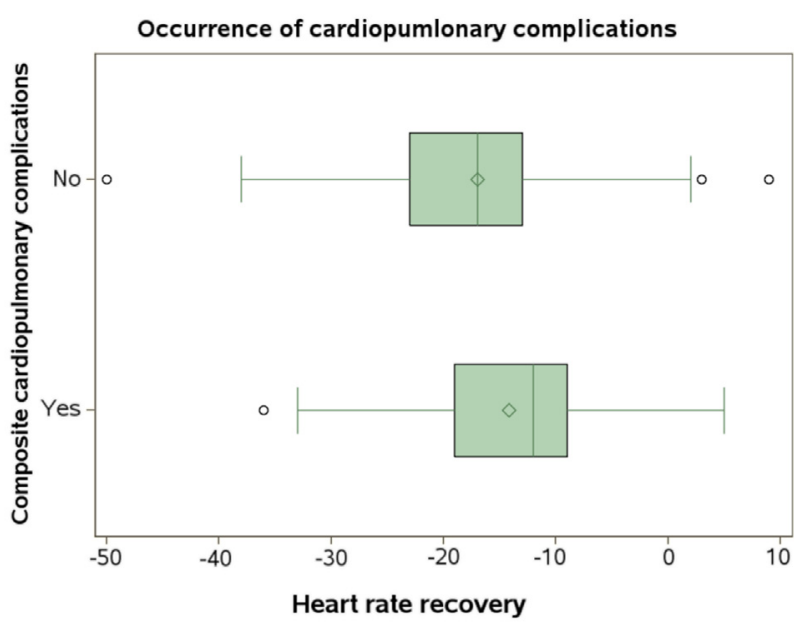

$\mathrm{CPC}=$ cardiopulmonary complications; $\mathrm{HRR}=$ heart rate recovery

FIGURE E1. Boxplot of HRR by CPC.
TABLE E2. Cardiopulmonary complications

\begin{tabular}{lccc}
\hline \multicolumn{1}{c}{ Complications } & $\begin{array}{c}\text { All } \\
\text { patients (n) }\end{array}$ & $\begin{array}{c}\text { Normal } \\
\text { HRR (n) }\end{array}$ & $\begin{array}{c}\text { Impaired } \\
\text { HRR (n) }\end{array}$ \\
\hline Atelectasis & 2 & 0 & 2 \\
Acute respiratory distress syndrome & 0 & 0 & 0 \\
Pulmonary embolism & 2 & 1 & 1 \\
Deep vein thrombosis & 2 & 1 & 1 \\
Pneumothorax & 1 & 0 & 1 \\
Respiratory failure at 24 h & 1 & 0 & 1 \\
Mechanical ventilation at 48 h & 1 & 0 & 1 \\
Tracheostomy & 1 & 0 & 1 \\
Pleural effusion \pm drainage & 16 & 9 & 7 \\
Pneumonia & 1 & 1 & 0 \\
Empyema & 1 & 1 & 0 \\
Other pulmonary complications & 2 & 1 & 1 \\
Atrial arrhythmia & 9 & 5 & 4 \\
Ventricular arrhythmia & 0 & 0 & 0 \\
Myocardial infarction & 0 & 0 & 0 \\
Other CPCs & 3 & 1 & 2 \\
Total complications* & 42 (in 96 & 20 (in 65 & 22 (in 31 \\
& patients) & patients) & patients)
\end{tabular}

$C P C$, Cardiopulmonary complication; HRR, heart rate recovery. ${ }^{*}$ There were 6 patients who had 2 complications, 3 of whom had impaired HRR; 1 patient had 3 complications had impaired HRR.
TABLE E1. Comparison of predictors of surgical complications

\begin{tabular}{lccc}
\hline \multicolumn{1}{c}{ Patient characteristics } & $\begin{array}{c}\text { Study } \\
\text { cohort } \\
(\mathbf{n}=\mathbf{9 6})\end{array}$ & $\begin{array}{c}\text { Comparative } \\
\text { cohorts } \\
(\mathbf{n}=\mathbf{4 7 5})\end{array}$ & $\begin{array}{c}\boldsymbol{P} \\
\text { value }\end{array}$ \\
\hline Age, y & $65.5(9.6)$ & $63.8(12.1)$ & .89 \\
Female, n (\%) & $46(47.9)$ & $220(46.3)$ & .64 \\
BMI, kg/m & $27.8(5.2)$ & $27.8(7.2)$ & .58 \\
Corticosteroid therapy, n (\%) & $10(10.4)$ & $26(5.5)$ & .07 \\
Preoperative chemotherapy, n (\%) & $10(10.4)$ & $67(14.1)$ & .33 \\
Prior CT surgery, n (\%) & $16(16.7)$ & $84(17.7)$ & .63 \\
Creatinine, mg/dL & $0.9(0.3)$ & $0.92(0.35)$ & .20 \\
Hemoglobin, g/dL & $13.3(1.4)$ & $13.3(1.6)$ & .56 \\
FEV, \% predicted & $81.5(20.1)$ & $83.1(18.7)$ & .37 \\
DL $\mathrm{CO}, \%$ predicted & $71.0(16.9)$ & $74.4(17.2)$ & .19 \\
ASA PS, n (\%) & & & .65 \\
I & $0(0.0)$ & $5(1.1)$ & \\
II & $4(4.2)$ & $27(5.7)$ & \\
III & $68(70.8)$ & $316(66.5)$ & \\
IV & $24(25.0)$ & $127(26.7)$ & \\
Clinical stage, n (\%) & & & .35 \\
I & $61(64.3)$ & $332(68.2)$ & \\
II & $22(23.2)$ & $75(15.9)$ & \\
III & $9(9.4)$ & $60(12.7)$ & \\
IV & $1(1.1)$ & $15(3.2)$ & \\
\hline ASA A & &
\end{tabular}

$A S A$, American Society Anesthesiologists; $B M I$, body mass index; $C T$, cardiothoracic; $D L_{C O}$, diffusion capacity of carbon monoxide; $F E V_{l}$, forced expiratory volume within 1 second; $P S$, performance status. *The Student $t$ tests and Pearson's chi-square tests were used to test for potential differences between our study cohort and other patients with lung cancer receiving surgery in the same time period. Values are expressed as means and standards of deviation, unless specified. 
TABLE E3. Baseline characteristics of patients who received stereotactic body radiation therapy

\begin{tabular}{|c|c|}
\hline Patient characteristics & Value $(N=49)$ \\
\hline Age, y, mean (range) & $71(48-88)$ \\
\hline \multicolumn{2}{|l|}{ Race, n (\%) } \\
\hline Caucasian & $40(82)$ \\
\hline \multicolumn{2}{|l|}{ Gender, n (\%) } \\
\hline Female & $24(49)$ \\
\hline \multicolumn{2}{|l|}{ Smoking status, n (\%) } \\
\hline Current & $15(31)$ \\
\hline Former & $32(65)$ \\
\hline \multicolumn{2}{|l|}{ Clinical stage, $\mathrm{n}(\%)$} \\
\hline Ia & $35(71)$ \\
\hline $\mathrm{Ib}$ & $10(20)$ \\
\hline IIa & $2(4)$ \\
\hline IIb & $2(4)$ \\
\hline \multicolumn{2}{|l|}{ Lobe involved, n (\%) } \\
\hline RUL & $12(25)$ \\
\hline RML & $3(6)$ \\
\hline RLL & $8(16)$ \\
\hline LUL & $22(45)$ \\
\hline LLL & $4(8)$ \\
\hline \multicolumn{2}{|l|}{ Lung function, mean (range) } \\
\hline $\mathrm{FEV}_{1}, \%$ predicted & $60.9(19.0-126.0)$ \\
\hline $\mathrm{DL}_{\mathrm{CO}}, \%$ predicted & $43.8(11.0-86.0)$ \\
\hline ppoFEV $_{1}, \%$ predicted & $47.0(14.0-92.8)$ \\
\hline ppoDL $_{\mathrm{CO}}, \%$ predicted & $33.9(8.1-72.4)$ \\
\hline PPP & $1642(299-5131)$ \\
\hline KPS, mean (range) & $81(60-100)$ \\
\hline Impaired HRR, n (\%) & $32(65)$ \\
\hline
\end{tabular}

